\title{
Strain Rate Dependent Deformation of a Polymer Matrix Composite with Different Microstructures Subjected to Off-Axis Loading
}

\author{
Xiaojun Zhu, Xuefeng Chen, Zhi Zhai, Zhibo Yang, Xiang Li, and Zhengjia He \\ State Key Lab for Manufacturing Systems Engineering, Xian Jiaotong University, Xian 710049, China \\ Correspondence should be addressed to Xuefeng Chen; chenxf@mail.xjtu.edu.cn
}

Received 24 April 2014; Accepted 2 June 2014; Published 23 June 2014

Academic Editor: Weihua Li

Copyright (c) 2014 Xiaojun Zhu et al. This is an open access article distributed under the Creative Commons Attribution License, which permits unrestricted use, distribution, and reproduction in any medium, provided the original work is properly cited.

This paper aims to investigate the comprehensive influence of three microstructure parameters (fiber cross-section shape, fiber volume fraction, and fiber off-axis orientation) and strain rate on the macroscopic property of a polymer matrix composite. During the analysis, AS4 fibers are considered as elastic solids, while the surrounding PEEK resin matrix exhibiting rate sensitivities are described using the modified Ramaswamy-Stouffer viscoplastic state variable model. The micromechanical method based on generalized model of cells has been used to analyze the representative volume element of composites. An acceptable agreement is observed between the model predictions and experimental results found in the literature. The research results show that the stressstrain curves are sensitive to the strain rate and the microstructure parameters play an important role in the behavior of polymer matrix.

\section{Introduction}

In the last few decades, polymer matrix composite materials (PMCs) have been developed rapidly to meet the demands for better materials with higher standards of performance and reliability in structures and machines $[1,2]$. In some of these applications such as marine structures, aerospace, and lightweight armor, the PMCs are often subjected to complex loadings under extreme circumstances $[3,4]$ in which the properties of the PMCs exhibit highly nonlinear and rate dependence, so it is necessary for structural design and analysis to characterize and model the nonlinearity and strain rate dependence of the composite.

Polymers are known to have a strain rate dependent deformation response that is nonlinear above 1 or $2 \%$ strain [5]. Many experimental studies have been made to determine the effects of strain rate on the PMCs [6]. Weeks [7] conducted experiments using an MTS machine and the split Hopkinson pressure bar for AS4/PEEK composite and produced strain rates ranging from $0.00001 / \mathrm{s}$ to $1000 / \mathrm{s}$. Uniaxial tension tests were conducted on various off-axis coupon specimens to obtain stress/strain curves for various strain rates [8]. Haque and Ali [9] adopted a systematic experimental approach to identify the damage progression at various stress levels and the strain rate effects on composites. Shokrieh and Omidi [10] studied tensile failure properties unidirectional glass/epoxy composites at various strain rates from $0.001 / \mathrm{s}$ to $100 / \mathrm{s}$ using a high-speed servohydraulic testing apparatus. Experimental results showed a significant increase of the tensile strength by increasing the strain rate.

On the other hand, there are also many macromechanical and micromechanical models to predict the behavior of composite materials subjected to different strain rates [11, 12]. Weeks and Sun [13] developed a macromechanical, rate dependent constitutive model to analyze the inelastic response of carbon reinforced composites. Thiruppukuzhi and Sun [14] later directly incorporated the rate dependence of the material response into the constitutive model. Espinosa et al. [15] presented a 3D finite deformation anisotropic viscoplasticity model to analyze the effects of strain rate and temperature on a woven composite made of S-2 glass fibers. A 3D model based on finite elastoplasticity was applied to study the effect of temperature and strain rate on the tensile behaviour on a series of polymeric matrix unidirectional glass-fibre composites [16]. Recently, a Johnson-Cook based 


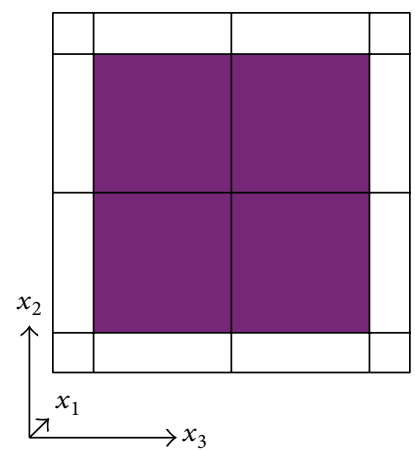

(a) Square

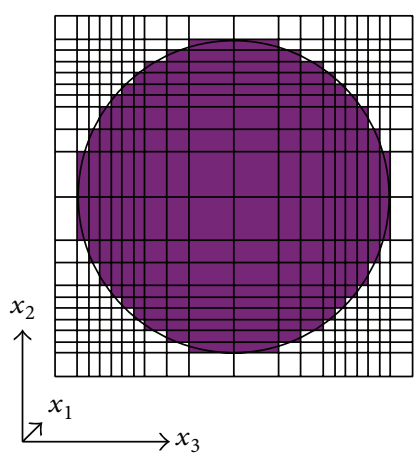

(b) Circular

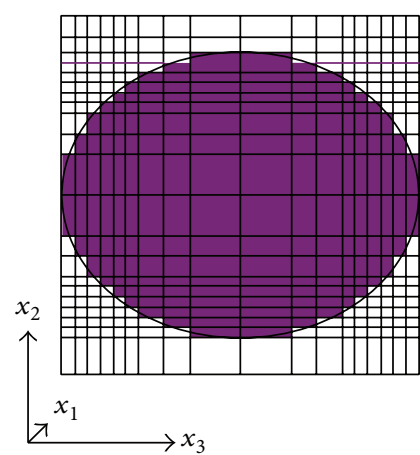

(c) Elliptical

FIGURE 1: Three kinds of fiber shapes.

modeling approach was used to represent the apparent strain rate dependency of textile reinforced composites in laminate through-thickness direction [17]. A phenomenological-based approach was proposed by Raimondo et al. [18] for the three-dimensional modeling of strain rate in unidirectional polymer composites. A nonlinear constitutive model for large deformation loading at different strain rate condition was developed to represent tensile progressive damage of the nonlinear large deformation rate dependent behavior of polymer-based composite materials [19].

Compared with macromechanical model, which considered composites as anisotropic medium with homogeneous distribution, the micromechanical model only needs to test the ingredient properties of composites, while macromechanical model needs to do repetitive experiments for composites [20]. Therefore, many scholars have done a lot of research on the micromechanical model for years. A 3D micromechanical formulation was proposed [21] for fiber composites with viscoplastic matrix properties. The nonlinear responses of composites under various cyclic loading conditions were predicted accurately by their analysis. Goldberg and Stouffer [22] adopted a four-region micromechanics method, in which the composite unit cell is divided into a number of slices to analyze polymer matrix composites subject to different strain rates. Later, the micromechanical model was implemented in the nonlinear finite element software LS-DYNA [23]. By combining the bridging micromechanics model [24] with classical lamination, a general constitutive relationship was established for the inelastic and failure analysis of laminate structures [25]. Paley and Aboudi [26] proposed the generalized method of cells (GMC) to deal with the representative volume element (RVE) with complex microstructures. Ogihara et al. [27] adopted the GMC to study the nonlinear behavior of unidirectional carbon-epoxy laminates subjected to off-axis loading. The epoxy matrix was predicted using the one-parameter plasticity model. Tsai and Chen [28] employed the GMC to characterize the nonlinear rate-dependent behaviors of graphite/epoxy composites. The epoxy matrix is described by a three-parameter viscoplasticity model. However, the comprehensive effect of three microstructure parameters (fiber cross-section shape, fiber volume fraction, and fiber off-axis orientation) and the strain rate on the macroscopic property of composites has been seldom reported in the above studies. In this paper, by combining the GMC with the modified Ramaswamy-Stouffer viscoplastic state variable model, and with no need to judge whether the material is in elastic or plastic stage and is more convenience and effective to predict the matrix behavior [29], a new general constitutive relationship was established for the inelastic analysis of the comprehensive influence of three microstructure parameters and strain rate on the stress-strain behavior of the polymer matrix composite.

In this paper, the rest outline is as follows. Section 2 introduces the micromechanical model based GMC. In Section 3, the modified Ramaswamy-Stouffer viscoplastic state variable model is incorporated into GMC. Composites with three microstructure parameters are considered to analyze the rate dependent stress-strain response in Section 4. Conclusions are given in Section 5.

\section{Micromechanical Model Based Generalized Model of Cells}

2.1. Generalized Model of Cells. The two-dimensional generalized method of cells is a micromechanical model developed originally by Paley and Aboudi [26] for predicting the response of unidirectional matrix composites with periodic microstructures. The GMC was then reformulated in terms of the interfacial subcell tractions substituting the subcell strains as the basic unknowns by Pindera and Bednarcyk [30], which can significantly increase the calculation efficiency when the number of subcells became larger.

When a micromechanical approach is used to model the mechanical response of fiber reinforced composites with periodic microstructures, a proper RVE is required to represent the microstructures of the materials such that the overall composites responses can be predicted directly from the representative volume element. In this study, three kinds of fiber cross-section shapes, such as square, circular, and elliptical, were considered as shown in Figure 1. In this figure, the fiber and matrix are indicated by the black and white, respectively.

In the GMC analysis, the representative volume element is usually divided into $N_{\beta} \times N_{\gamma}$ subcells as shown in Figure 2 . 


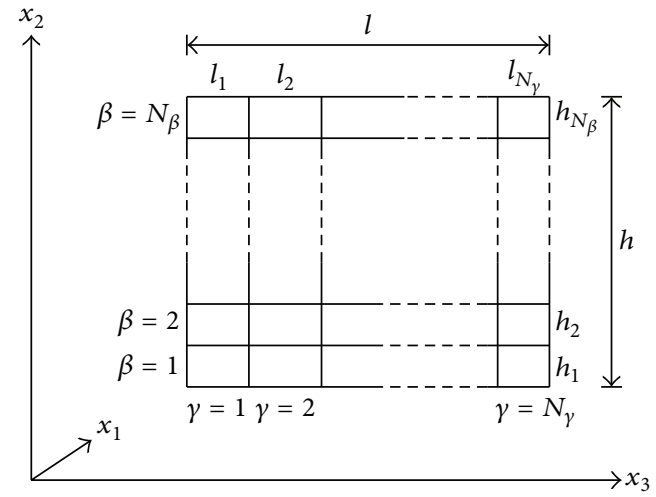

Figure 2: A typical RVE divided into $N_{\beta} \times N_{\gamma}$ subcells in GMC analysis.

In general, each of these subcells is assumed to be occupied by a material that exhibits inelastic behavior. The subcell material's inelastic behavior can be modeled by a lot of constitutive theories, such as classical incremental plasticity, linear viscoelasticity, or unified viscoplasticity theories. Therefore, the representative volume element, which consists of $N_{\beta} \times$ $N_{\gamma}$ different inelastic materials, can represent a multiphased, inelastic composite.

Based on the displacement continuity on the interface of the adjacent subcells in conjunction with the periodicity condition of the RVE, the relation between overall strain and the subcell strain is expressed as

$$
\overline{\boldsymbol{\varepsilon}}^{(\beta \gamma)}=\mathbf{A}^{(\beta \gamma)} \overline{\boldsymbol{\varepsilon}}
$$

where $(\beta \gamma)$ indicates the subcell whose location in RVE is at the $\beta$ th row and $\gamma$ th column, and $\mathbf{A}$ is the matrix linking the micro- and macrostrain.

At the same time, the interfacial traction continuity conditions can be expressed as

$$
\begin{gathered}
\bar{\sigma}_{22}^{(1 \gamma)}=\bar{\sigma}_{22}^{(2 \gamma)}=\cdots=\bar{\sigma}_{22}^{\left(N_{\beta} \gamma\right)}=\mathbf{T}_{22}^{(\gamma)} \quad\left(\gamma=1, \ldots, N_{\gamma}\right), \\
\bar{\sigma}_{33}^{(\beta 1)}=\bar{\sigma}_{33}^{(\beta 2)}=\cdots=\bar{\sigma}_{33}^{\left(\beta N_{\gamma}\right)}=\mathbf{T}_{33}^{(\beta)} \quad\left(\beta=1, \ldots, N_{\beta}\right), \\
\bar{\sigma}_{21}^{(1 \gamma)}=\bar{\sigma}_{21}^{(2 \gamma)}=\cdots=\bar{\sigma}_{21}^{\left(N_{\beta} \gamma\right)}=\mathbf{T}_{21}^{(\gamma)}=\mathbf{T}_{12}^{(\gamma)} \\
\left(\gamma=1, \ldots, N_{\gamma}\right), \\
\bar{\sigma}_{31}^{(\beta 1)}=\bar{\sigma}_{31}^{(\beta 2)}=\cdots=\bar{\sigma}_{31}^{\left(\beta N_{\gamma}\right)}=\mathbf{T}_{31}^{(\beta)}=\mathbf{T}_{13}^{(\beta)} \\
\left(\beta=1, \ldots, N_{\beta}\right) \\
\bar{\sigma}_{23}^{(1 \gamma)}=\bar{\sigma}_{23}^{(2 \gamma)}=\cdots=\bar{\sigma}_{23}^{\left(N_{\beta} \gamma\right)}=\mathbf{T}_{23}^{(\gamma)}=\mathbf{T}_{23} \\
\left(\gamma=1, \ldots, N_{\gamma}\right) \\
\bar{\sigma}_{32}^{(\beta 1)}=\bar{\sigma}_{32}^{(\beta 2)}=\cdots=\bar{\sigma}_{32}^{\left(\beta N_{\gamma}\right)}=\mathbf{T}_{32}^{(\beta)}=\mathbf{T}_{23} \\
\left(\beta=1, \ldots, N_{\beta}\right) .
\end{gathered}
$$

For each subcell of composites, the constitutive relationship of each subcell can be written as

$$
\overline{\boldsymbol{\varepsilon}}^{(\beta \gamma)}=\mathbf{S}^{(\beta \gamma)} \bar{\sigma}^{(\beta \gamma)}+\overline{\boldsymbol{\varepsilon}}^{p(\beta \gamma)}+\boldsymbol{\alpha}^{(\beta \gamma)} \Delta T
$$

Substituting (3) into (1) and then combining (2), the relations between subcell tractions and overall strains can be obtained as

$$
\bar{\sigma}_{i j}^{(\beta \gamma)}=\mathbf{C}_{i j k l}^{(\beta \gamma)} \mathbf{A}^{(\beta \gamma)} \overline{\boldsymbol{\varepsilon}}
$$

Based on the homogenization theory, the overall stress of the RVE can be written as

$$
\overline{\boldsymbol{\sigma}}=\frac{1}{h l} \sum_{\beta=1}^{N_{\beta}} \sum_{\gamma=1}^{N_{\gamma}} h_{\beta} l_{\gamma} \overline{\boldsymbol{\sigma}}^{(\beta \gamma)} .
$$

Substituting (4) into (5), the overall stress and strain relation of the RVE are established as

$$
\overline{\boldsymbol{\sigma}}=\mathbf{C}^{*}\left(\overline{\boldsymbol{\varepsilon}}-\overline{\boldsymbol{\varepsilon}}^{p}-\boldsymbol{\alpha}^{*} \Delta T\right),
$$

where $\mathbf{C}^{*}$ indicates the overall elastic stiffness matrix, $\overline{\boldsymbol{\varepsilon}}^{p}=$ $\left[\bar{\varepsilon}_{11}^{p}, \bar{\varepsilon}_{22}^{p}, \bar{\varepsilon}_{33}^{p}, \bar{\varepsilon}_{23}^{p}, \bar{\varepsilon}_{13}^{p}, \bar{\varepsilon}_{12}^{p}\right]^{T}$ indicates the overall plastic strain, and $\boldsymbol{\alpha}^{*}=\left[\alpha_{11}^{*}, \alpha_{22}^{*}, \alpha_{33}^{*}\right]^{T}$ represents the overall thermal expansion coefficient vector.

It should be noted that the elements of matrixes $\mathbf{C}^{*}, \overline{\boldsymbol{\varepsilon}}^{p}$, and $\boldsymbol{\alpha}^{*}$ can be explicitly obtained in terms of the subcell material and geometric parameters and subcell plastic strains, so when the subcell ingredient properties and the RVE geometry are known, (6) can be used to model the responses of fiber composites.

\section{Viscoplastic Constitutive Model}

The matrix viscoplastic constitutive model is based on the modified Ramaswamy-Stouffer viscoplastic state variable model. The Ramaswamy-Stouffer viscoplastic state variable model [31] was originally developed to simulate the rate dependent inelastic response of metals. However, the relationship between load and deformation in resins is more complicated than that in metals since the hydrostatic component of the stress has a significant effect even at low level of stress [32]. The effect of the hydrostatic stresses was considered by modifying the effective stress term in the flow law of Ramaswamy-Stouffer model [22]. In the modified Ramaswamy-Stouffer model, the total strain rate, $\dot{\varepsilon}_{i j}$, is composed of elastic strain rate, $\dot{\varepsilon}_{i j}^{e}$, and inelastic strain rate, $\dot{\varepsilon}_{i j}^{I}$; that is,

$$
\dot{\varepsilon}_{i j}=\dot{\varepsilon}_{i j}^{e}+\dot{\varepsilon}_{i j}^{I}
$$

The elastic strain rate can be obtained according to the time derivative of Hook's law. The inelastic strain rate is defined in the following form:

$$
\dot{\varepsilon}_{i j}^{I}=D_{0} \exp \left[-\frac{1}{2}\left(\frac{Z_{0}^{2}}{3 K_{2}}\right)^{n}\right] \times \frac{s_{i j}-\Omega_{i j}}{\sqrt{K_{2}}},
$$


where $D_{0}, Z_{0}$, and $n$ are all material constants. $D_{0}$ denotes the maximum inelastic strain rate, $Z_{0}$ indicates the initial, isotropic "hardness" of the material before any load is applied, $n$ represents the rate dependence of deformation response, $S_{i j}$ is the deviatoric stress component, and $\Omega_{i j}$ is the internal stress state variable.

The relation between the internal stress rate, $\dot{\Omega}_{i j}$ and $\Omega_{i j}$, is defined as follows:

$$
\dot{\Omega}_{i j}=\frac{2}{3} q \Omega_{m} \dot{\varepsilon}_{i j}-q \Omega_{i j} \dot{\varepsilon}_{e}^{I},
$$

where $q$ and $\Omega_{m}$ are both material constants. $q$ represents the "hardening" rate, $\Omega_{m}$ represents the maximum value of the internal stress, and $\dot{\varepsilon}_{e}^{I}$ is the effective inelastic strain rate, which is defined as follows:

$$
\dot{\varepsilon}_{i j}^{I}=\sqrt{\frac{2}{3} \dot{\varepsilon}_{i j} \dot{\varepsilon}_{i j}}
$$

The term $K_{2}$, which represents the effective stress, is defined in the original Ramaswamy-Stouffer model in the following form:

$$
K_{2}=\frac{1}{2}\left(S_{i j}-\Omega_{i j}\right)\left(S_{i j}-\Omega_{i j}\right) .
$$

In the modified Ramaswamy-Stouffer model, in order to consider the effect of hydrostatic stresses, (11) is rewritten as follows:

$$
K_{2}=\frac{1}{2}\left[K_{11}+K_{22}+K_{33}+2\left(K_{12}+K_{13}+K_{23}\right)\right] .
$$

The normal terms in the above expression are the same as the original definition while the shear terms are modified and can be written as

$$
\begin{aligned}
& K_{12}=\alpha\left(S_{12}-\Omega_{12}\right)\left(S_{12}-\Omega_{12}\right), \\
& K_{13}=\alpha\left(S_{13}-\Omega_{13}\right)\left(S_{13}-\Omega_{13}\right), \\
& K_{23}=\alpha\left(S_{23}-\Omega_{23}\right)\left(S_{23}-\Omega_{23}\right),
\end{aligned}
$$

where

$$
\alpha=\left(\frac{\sigma_{m}}{\sqrt{J_{2}}}\right)^{\beta} .
$$

In (14), $\sigma_{m}$ is the mean stress, $J_{2}$ is the second invariant of the deviatoric stress tensor, and $\beta$ is a rate independent material constant which is determined empirically by fitting data from uniaxial composites with shear dominated fiber orientation angles, such as $\left[15^{\circ}\right]$. The other material constants, such as $D_{0}, Z_{0}$, and $n$, are determined through the method discussed in the article written by Goldberg and Stouffer [22].

Through the above introduction of the modified Ramaswamy-Stouffer model, it can be seen that the model does not depend on the yield rule and the inelastic strains are assumed to be present at all values of stress. Therefore, there is no need to judge whether the material is in elastic or plastic stage.
TABLE 1: Material properties of PEEK resin [7].

\begin{tabular}{lccccccc}
\hline$E(\mathrm{GPa})$ & $v$ & $D_{0}(1 / \mathrm{sec})$ & $n$ & $Z_{0}(\mathrm{MPa})$ & $q$ & $\Omega_{m}(\mathrm{MPa})$ & $\beta$ \\
\hline 4.0 & 0.4 & $10^{4}$ & 0.7 & 630 & 310 & 52 & 0.40 \\
\hline
\end{tabular}

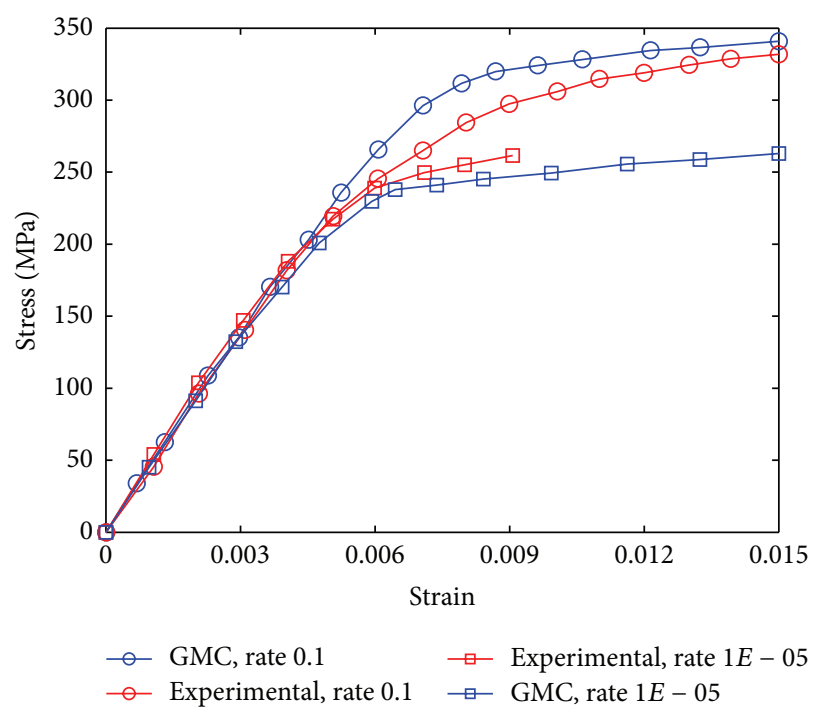

FIGURE 3: Stress-strain response of AS4/PEEK $\left[15^{\circ}\right]$ laminate at strain rate of $0.1 / \mathrm{sec}$ and $10^{-5} / \mathrm{sec}$.

\section{Results and Discussion}

4.1. Model Validation. To verify the ability of the micromechanics model and the viscoplastic constitutive model in the prediction of rate effects of composites several examples are considered and discussed in this section. The material considered here is a composite composed of carbon AS4 fibers in a PEEK thermoplastic matrix. For the AS4 fibers, the longitudinal elastic modulus is $214 \mathrm{GPa}$, the transverse and in-plane shear modulus is $14 \mathrm{GPa}$, the longitudinal Poisson's ratio is 0.2 , and the transverse Poisson's ratio is 0.25 [22]. The material properties of PEEK resin can be seen in Table 1. The fiber volume fraction $\left(v_{f}\right)$ used here is 0.62 and the fiber cross-section shape is square (seen in Figure 1). For comparison purposes, the experimental data obtained by Weeks [7] is shown as well. Two different strain rates, $0.1 / \mathrm{sec}$ and $10^{-5} / \mathrm{sec}$ (which is written as $1 \mathrm{E}-05$ in the figures for convenience), are considered. From Figures 3, 4, and 5, it can be seen that the results predicted by the presented micromechanics model and viscoplastic constitutive model exhibit good agreement with the experimental results.

\subsection{Stress-Strain Response of Composites with the Same Fiber} Volume Fraction but Different Fiber Shapes and Different Strain Rates in Different Fiber Off-Axis Orientations. Figure 6 presents the responses for $15^{\circ}, 45^{\circ}, 60^{\circ}$, and $75^{\circ}$ off-axis orientations in the case that composites contain 0.15 fiber volume fraction with different fiber shapes and strain rates. In the case of the elliptical fibers, the transverse loading is applied in the principal material directions of the long axis. In this kind of composites with very low fiber volume fraction, 


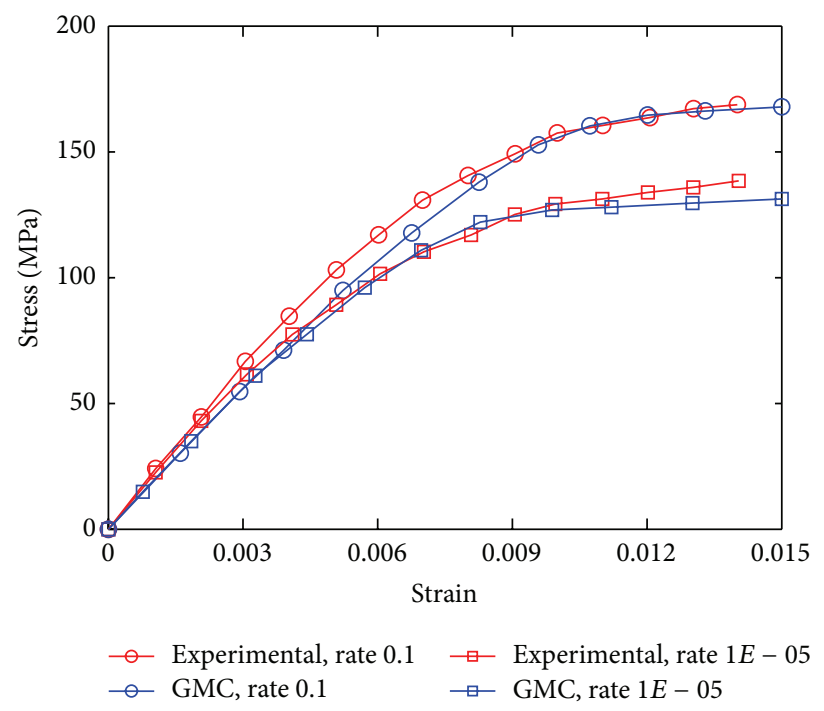

FIGURE 4: Stress-strain response of AS4/PEEK $\left[30^{\circ}\right]$ laminate at strain rate of $0.1 / \mathrm{sec}$ and $10^{-5} / \mathrm{sec}$.

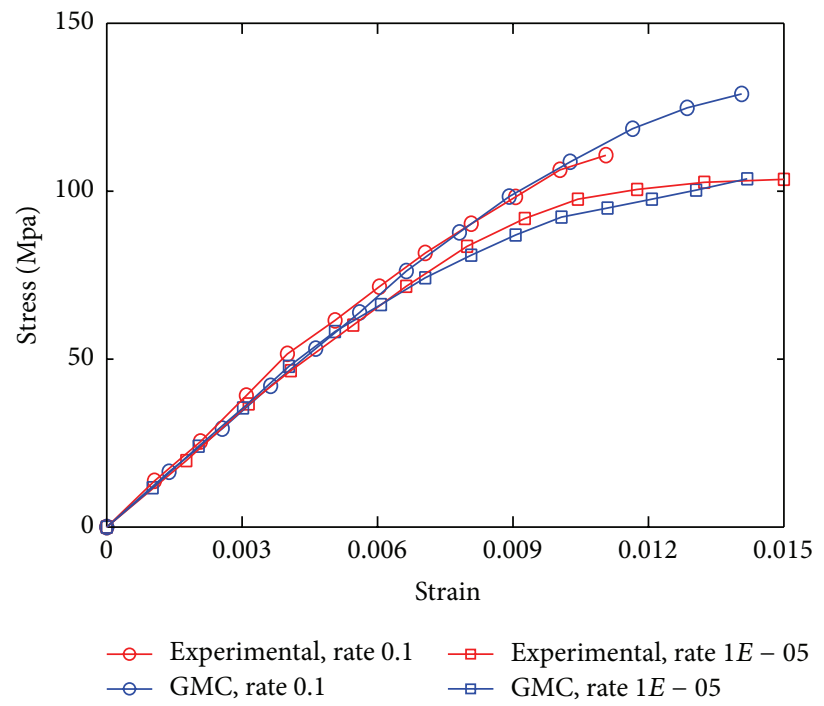

FIGURE 5: Stress-strain response of AS4/PEEK $\left[45^{\circ}\right]$ laminate at strain rate of $0.1 / \mathrm{sec}$ and $10^{-5} / \mathrm{sec}$.

the effect of fiber on the composites behavior is small, so it can be seen that the composites response is hardly affected by the fiber cross-section shape, but it could be affected by the off-axis orientation and the stain rate. Among the four kinds of off-axis orientations, the one with $15^{\circ}$ off-axis orientation exhibits the stiffest response while the one with $60^{\circ}$ off-axis orientation exhibits the most compliant response. For all the off-axis orientations, when the strain rate changes from $10^{-5} / \mathrm{sec}$ to $0.1 / \mathrm{sec}$, the composites provide an effective increase in the flow stress while the elastic behavior almost remain unchanged. This is because the fact that when the strain rate is smaller, the composites have more time to occur plastic flow and unload.

Increasing the fiber volume fraction further accentuates the differences in the composite's transverse response due to the fiber's cross-sectional shape. Figure 7 shows the stressstrain responses of composites when the fiber volume fraction is increased to 0.30 . It can be seen that when the off-axis angle is smaller than $75^{\circ}$, the composites response is hardly affected by the fiber cross-section shape. However, when the off-axis angle is increased to $75^{\circ}$, the effect of the fiber cross-sectional shape on the transverse response in the plastic region becomes discernible, with the square fibers being the most effective in increasing the flow stress of the composite. Figure $7(d)$ shows that the responses of composites with circular fibers and elliptical fibers with an aspect ratio of $4 / 3$ are almost the same, which are lower than the responses of composites with square fibers. With the increasing of the offaxis orientations of composites, the response of composites decreases first and then increases. 


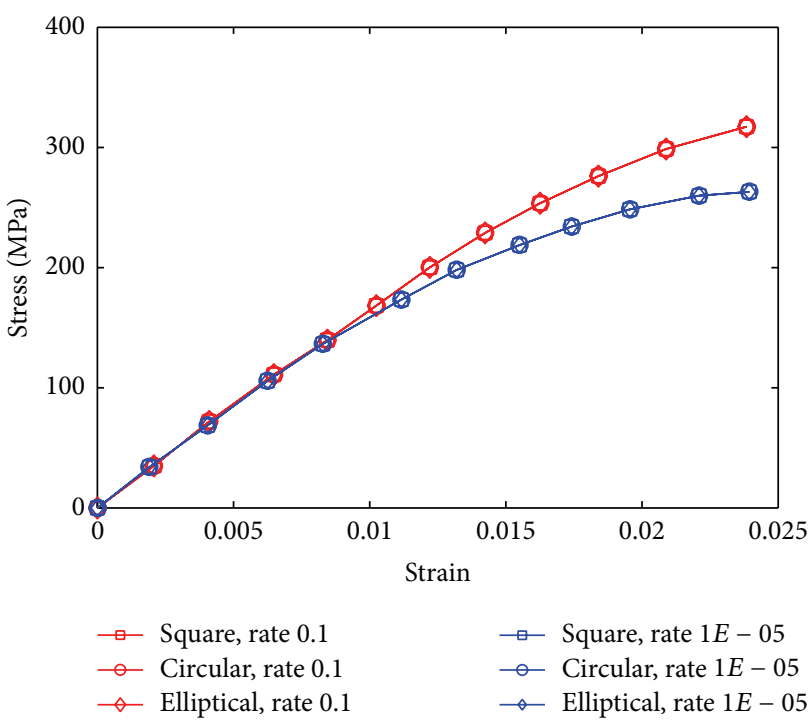

(a)

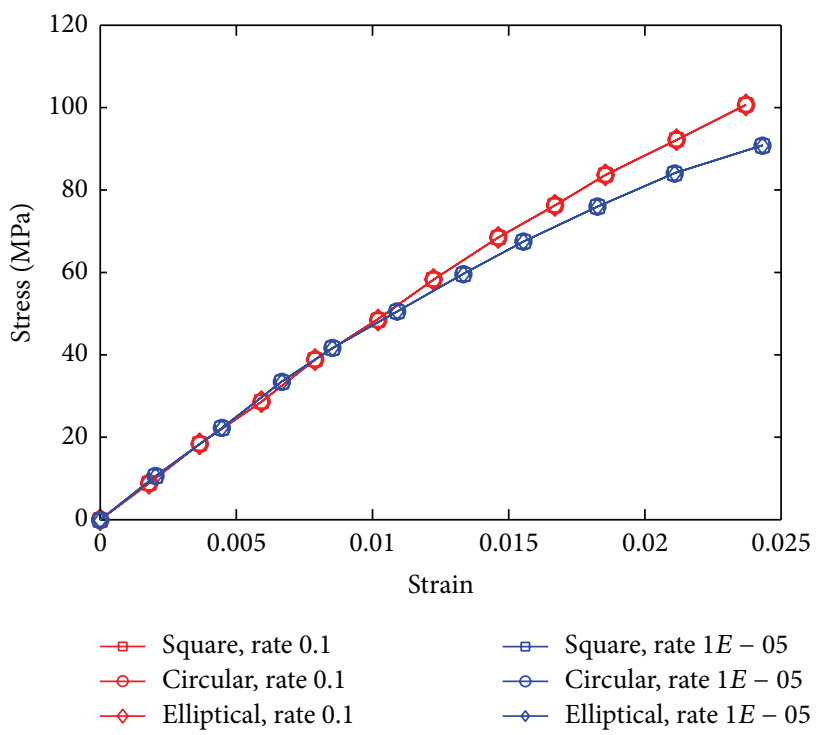

(c)

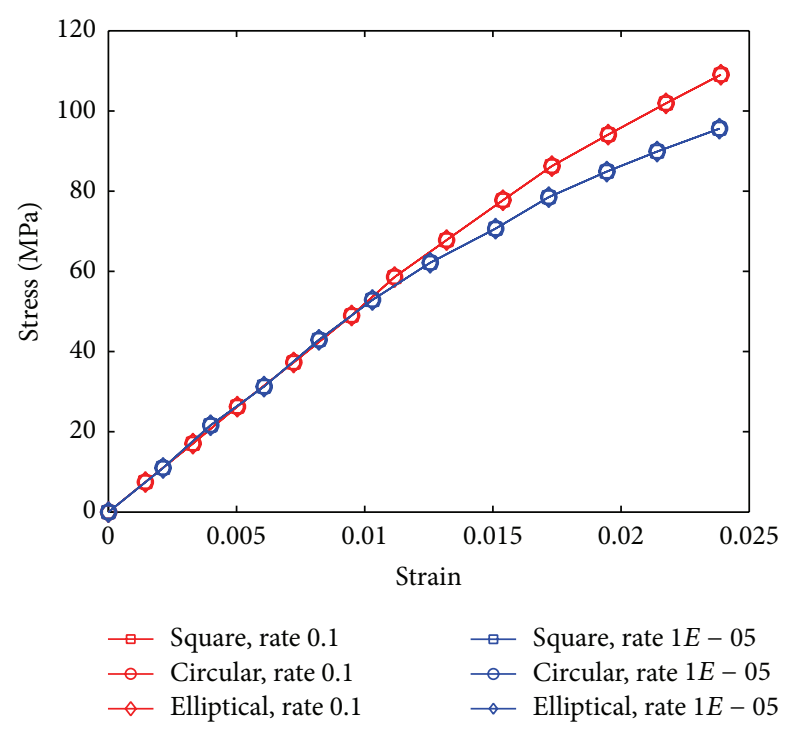

(b)

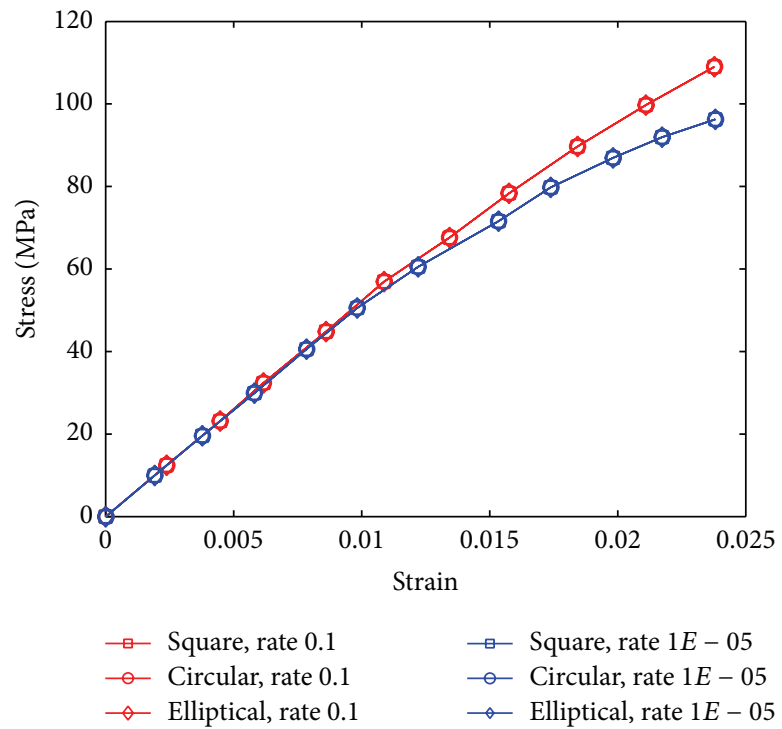

(d)

FIgURE 6: Off-axis responses of AS4/PEEK laminate $\left(v_{f}=0.15\right)$ at strain rate of $0.1 / \mathrm{sec}$ and $10^{-5} / \mathrm{sec}$ : (a) $15^{\circ}$, (b) $45^{\circ}$, (c) $60^{\circ}$, and (d) $75^{\circ}$.

Figure 8 presents the results that correspond to those shown in the preceding two figures when the fiber volume fraction is further increased to 0.45 . In this case, compared with the stress-strain curves when the fiber volume fraction is 0.30 , it can be seen that when the off-axis angle is $60^{\circ}$, the composites response has already been affected by the fiber cross-section shape although the difference is small. But when the off-axis angle is increased to $75^{\circ}$, a substantial difference between the unit cell with the square fiber and the remaining unit cells is now apparent in the plastic region. In Figure $8(\mathrm{~d})$, the square fiber provides a $20 \%$ increase in the transverse flow stress of the composite relative to that of the elliptical and circular fibers when the strain rate is $10^{-5} / \mathrm{sec}$, while the square fiber provides a $10 \%$ increase when the strain rate is $0.1 / \mathrm{sec}$. This is because the square fiber can provide a higher magnitude of hydrostatic stress in the matrix phase relative to the circular fiber, which can delay localized yielding and provide constraint on the expansion of the plastic zone throughout the matrix phase. When the strain rate is smaller, the composites have more time to occur plastic strain and unload. Therefore, it can be noted that when the strain rate is $10^{-5} / \mathrm{sec}$, the difference of composites response between the square fiber and the circular fiber is larger than the case when the strain rate is $0.1 / \mathrm{sec}$.

Figure 9 shows the stress-strain curves when the fiber volume fraction is increased to 0.55 . This fiber volume fraction is close to the maximum allowable for the RVE with the elliptical fiber, which is limited by the contact of fibers along the major axis in two adjacent RVE. This contact occurs when the fiber volume fraction is 0.59 in the case of fibers 


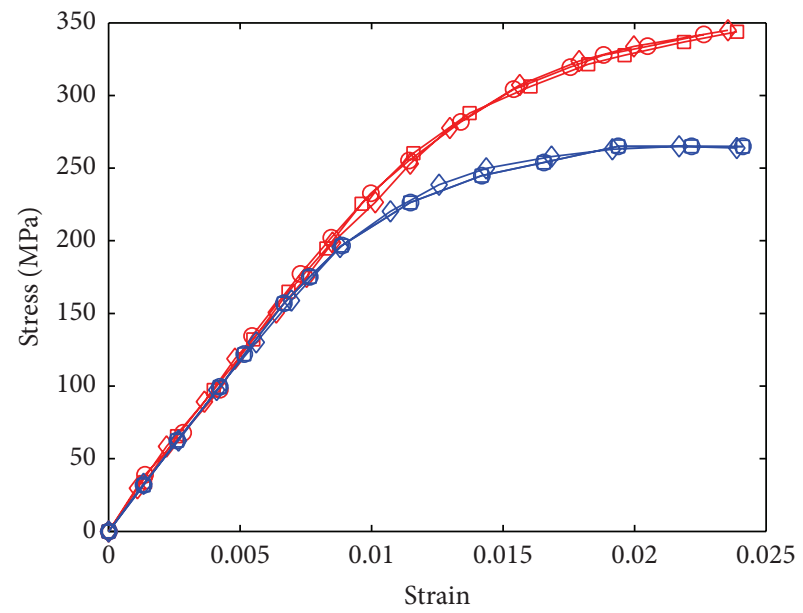

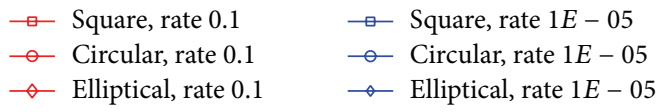

(a)
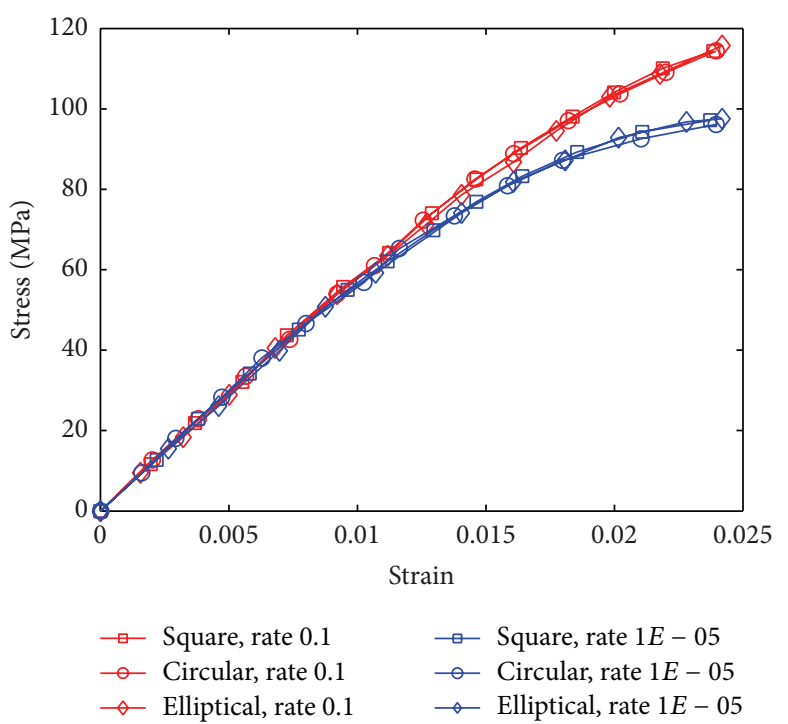

(c)

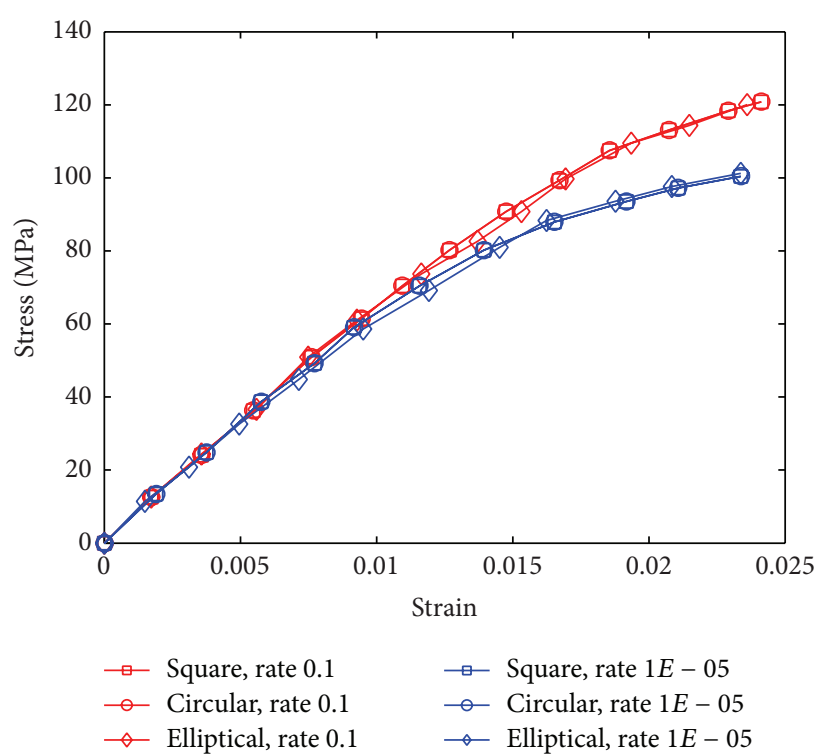

(b)
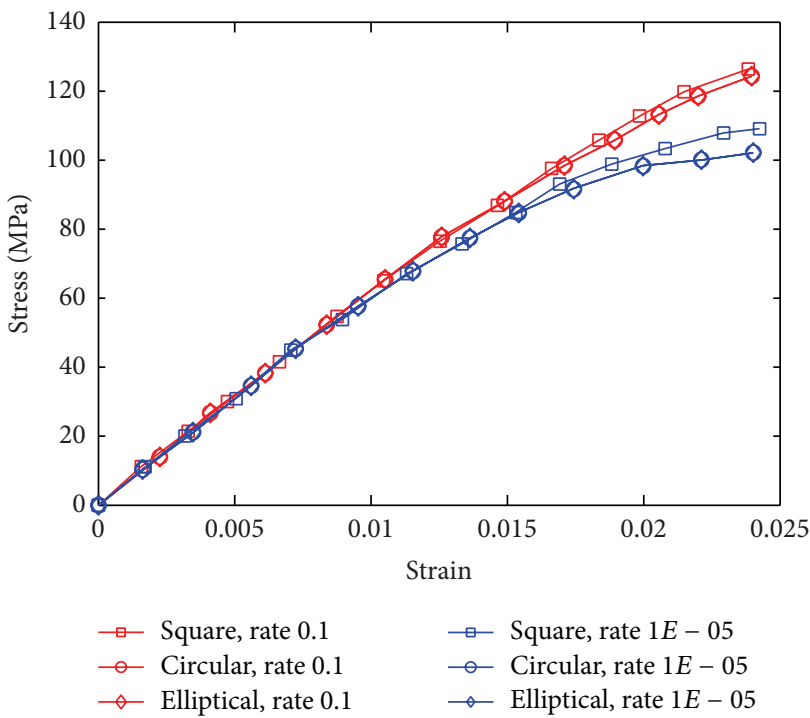

(d)

FIGURE 7: Off-axis responses of AS4/PEEK laminate $\left(v_{f}=0.30\right)$ at strain rate of $0.1 / \mathrm{sec}$ and $10^{-5} / \mathrm{sec}$ (a) $15^{\circ}$, (b) $45^{\circ}$, (c) $60^{\circ}$, and (d) $75^{\circ}$.

with an aspect ratio of $4 / 3$. From Figure $9(\mathrm{~b})$, it can be seen that the composites response is affected by the fiber crosssection shape when the off-axis angle is just $45^{\circ}$, which is smaller than the preceding cases. In additionally, for both of the two kinds of strain rates, the difference of the three kinds of fibers is more obvious with the increase of the off-axis angle. In Figure 9(d), the difference between the composites with square fibers and the composites with circular fibers is very big, and the response of the composites with square fibers at the strain rate of $10^{-5} / \mathrm{sec}$ is almost the same as the response of the composites with circular fibers at the strain rate of $0.1 / \mathrm{sec}$.

4.3. Stress-Strain Response of Composites with the Same Fiber Off-Axis Orientation but Different Fiber Shapes and Fiber Volume Fractions at Different Strain Rates. Figure 10 shows the stress-strain response for $0.15,0.30,0.45$, and 0.55 fiber volume fractions in the case that composites fiber off-axis angle is $90^{\circ}$. It can be seen that when the fiber volume fraction is less than 0.30 , the stress-strain response is barely affected by the fiber cross-section shapes. When the fiber volume fraction is more than 0.30 , the difference between different fiber cross-section shapes can be obtained. With the increase of the fiber volume fraction, the difference becomes larger and the stiffness of composites will increase, which is due to the bigger stiffness of fiber. When the fiber volume is increased to 0.45 , the response of the composites with square fibers at the strain rate of $10^{-5} / \mathrm{sec}$ is almost the same as the response rate of $0.1 / \mathrm{sec}$. When the fiber volume is increased to 0.55 , the response of the composites with square fibers at the strain rate of $10^{-5} / \mathrm{sec}$ is even higher than the response of the composites with circular fibers at the strain rate of $0.1 / \mathrm{sec}$. 


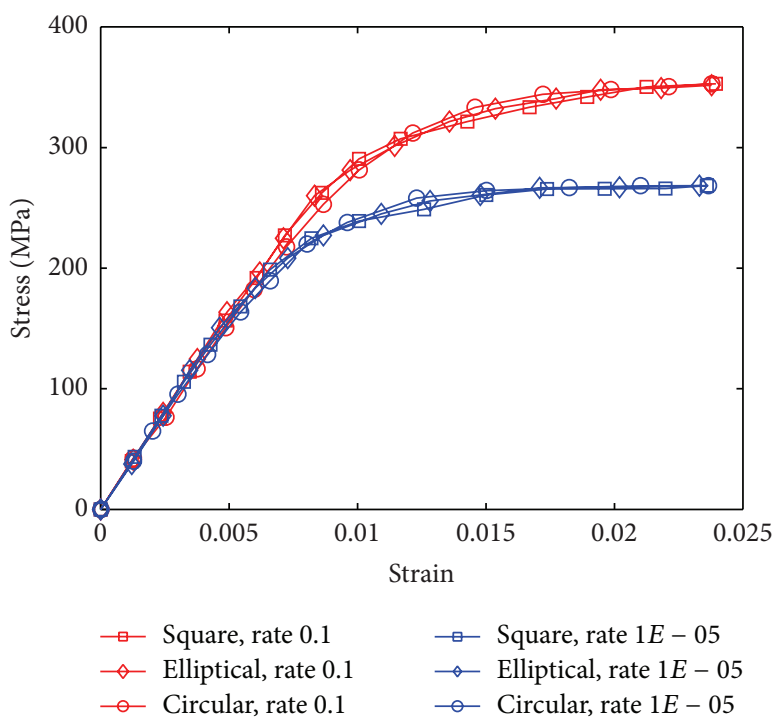

(a)

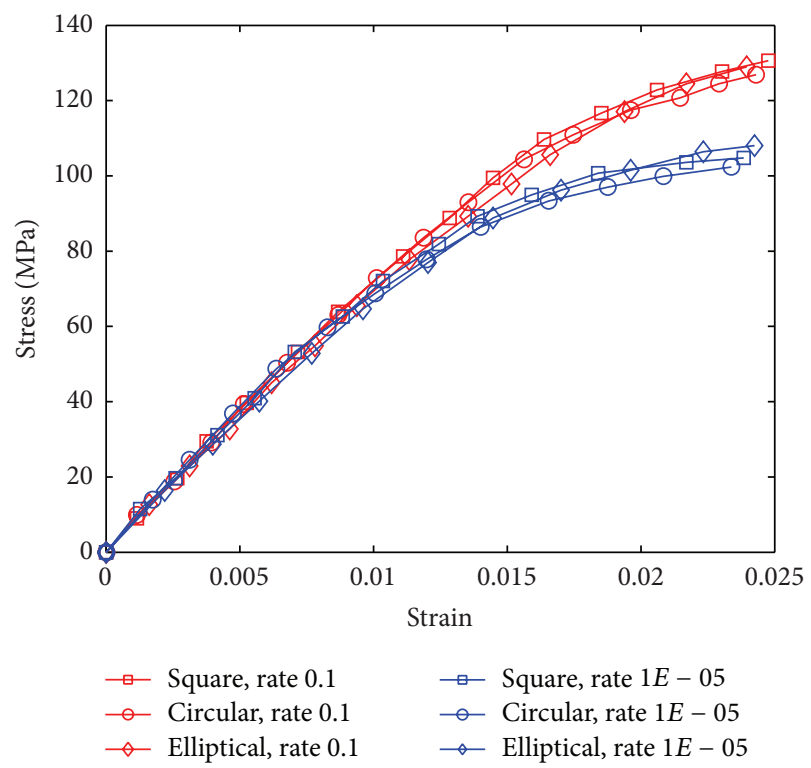

(c)

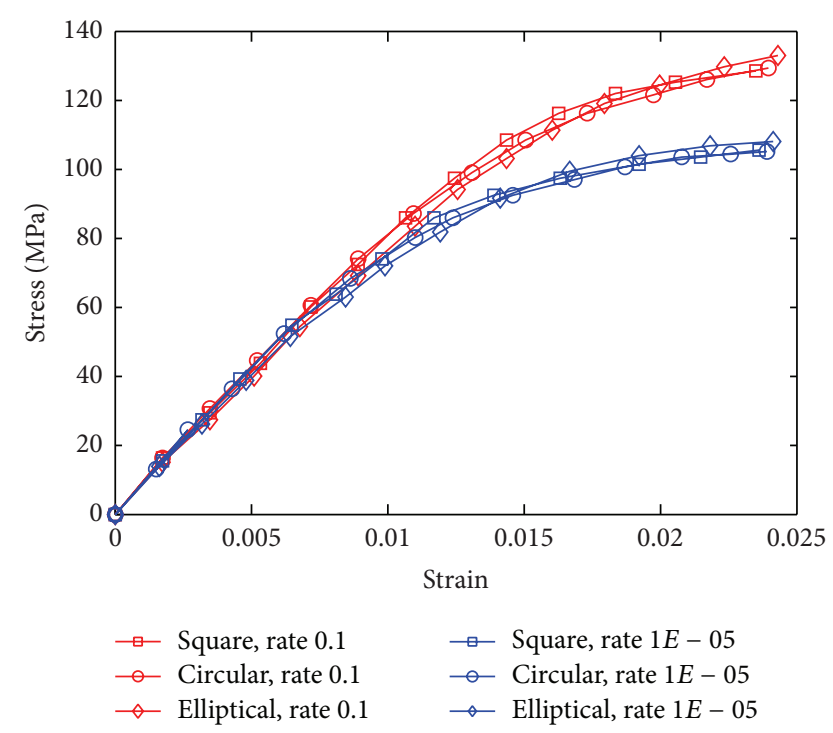

(b)

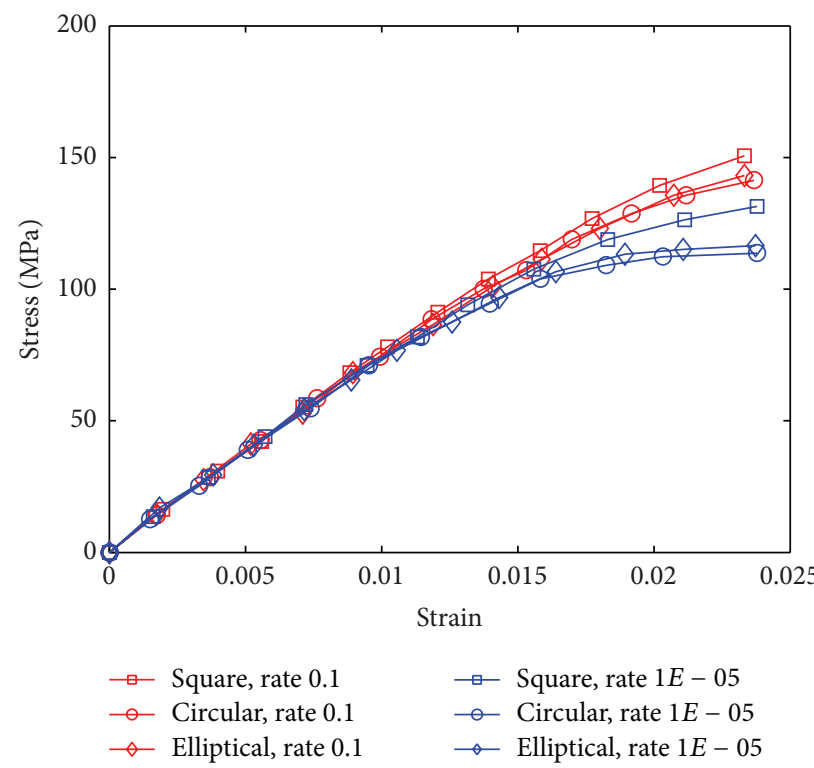

(d)

FIgURE 8: Off-axis responses of AS4/PEEK laminate $\left(v_{f}=0.45\right)$ at strain rate of $0.1 / \mathrm{sec}$ and $10^{-5} / \mathrm{sec}$ : (a) $15^{\circ}$, (b) $45^{\circ}$, (c) $60^{\circ}$, and $(\mathrm{d}) 75^{\circ}$.

In Figure 10(d), the square fiber provides a 33\% increase in the transverse flow stress of the composite relative to that of the elliptical and circular fibers when the strain rate is $10^{-5} / \mathrm{sec}$, while the square fiber provides a $15 \%$ increase when the strain rate is $0.1 / \mathrm{sec}$.

\section{Conclusions}

A viscoplastic constitutive model has been employed in the micromechanical method based on generalized model of cells to analyze the inelastic, rate dependent stress-strain response of fiber-reinforced polymer matrix composites with three different microstructures at different fiber off-axis angles condition. The acceptable agreement between the model predictions and experimental results shows that the proposed model can well predict the behaviors of AS4/PEEK composite. At the same time, from the predicted results, the following conclusions are obtained.

(1) The AS4/PEEK composite is a kind of rate dependent material. When the strain rate changes from $10^{-5} / \mathrm{sec}$ to $0.1 / \mathrm{sec}$, the composites provide an effective increase in the flow stress while the elastic behavior almost remain unchanged.

(2) The effects of fiber cross-sectional shape on the behavior of AS4/PEEK composite are related to the fiber volume fraction and fiber off-axis orientation. When the fiber volume fraction is smaller than 0.15 , it can be 


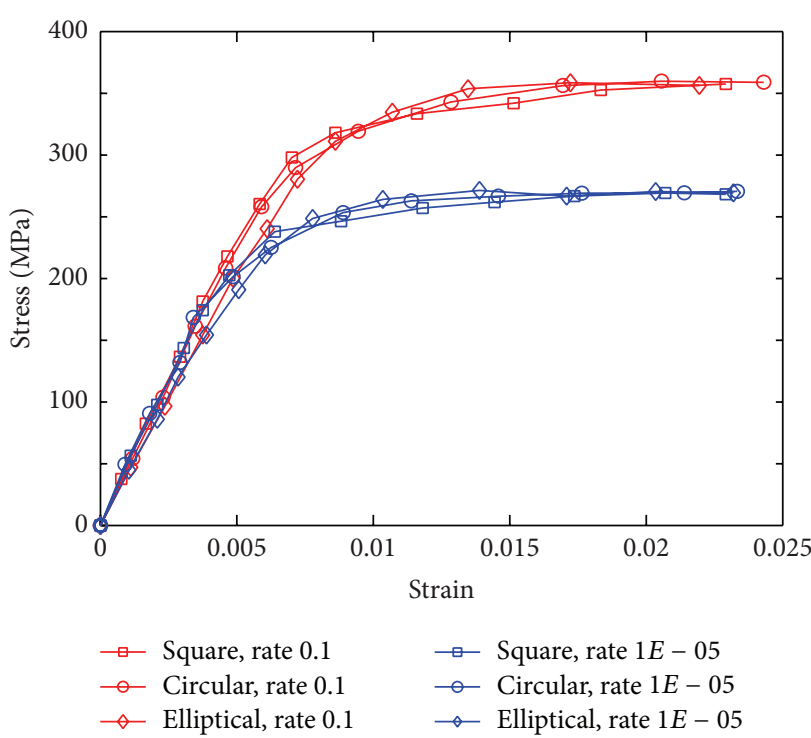

(a)

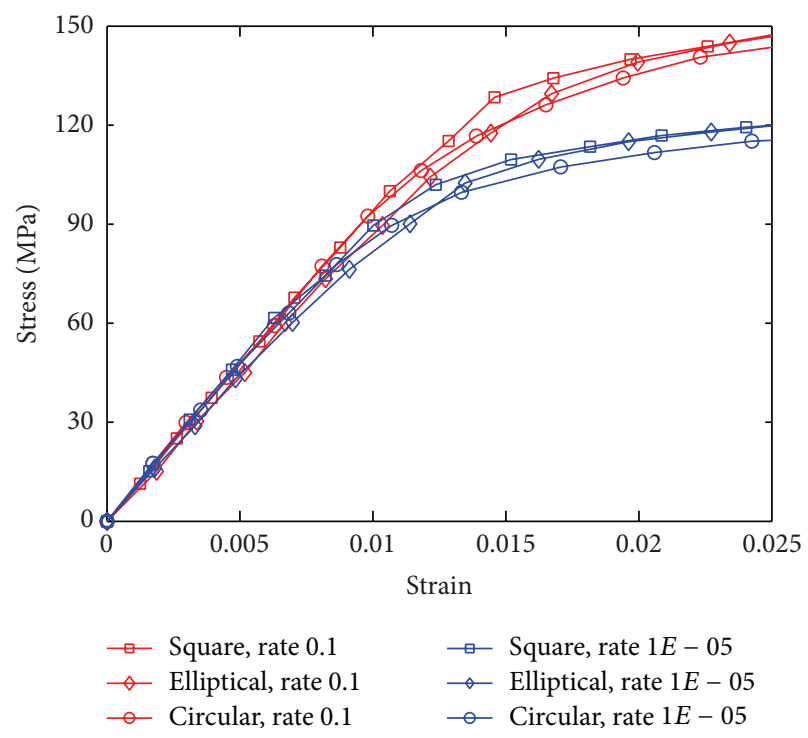

(c)

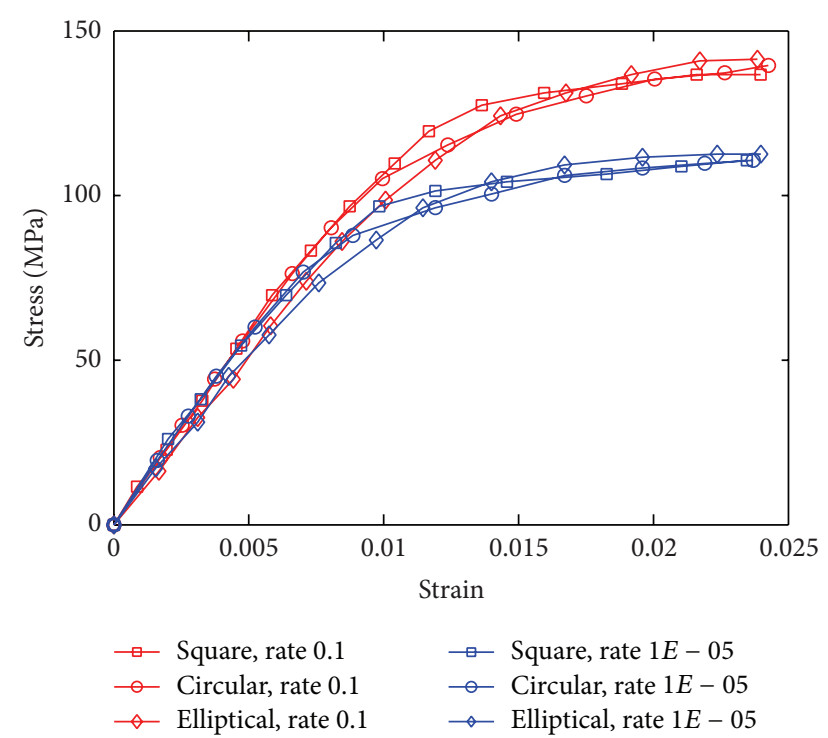

(b)

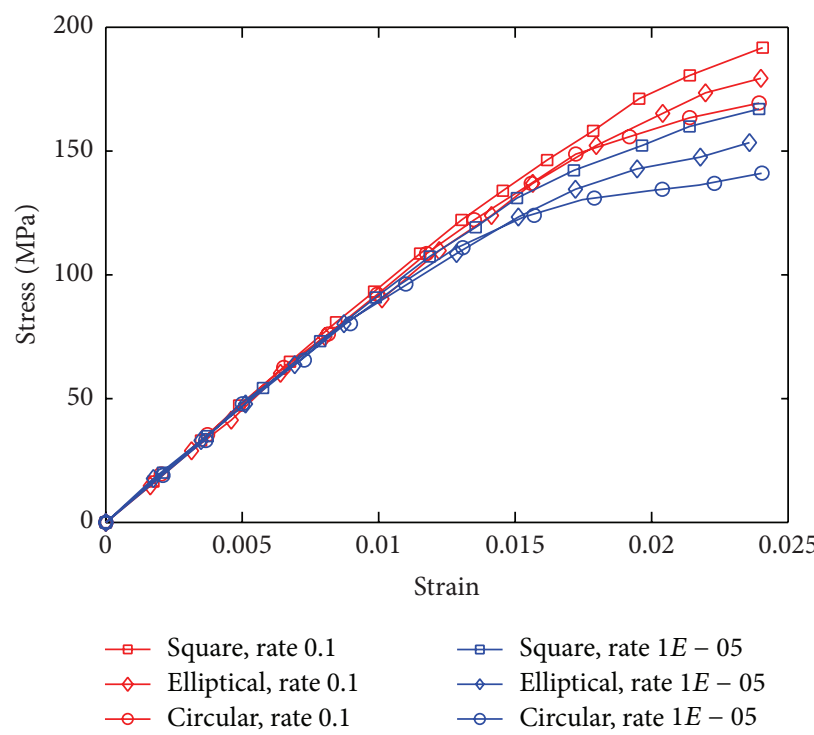

(d)

FIGURE 9: Off-axis responses of AS4/PEEK laminate $\left(v_{f}=0.55\right)$ at strain rate of $0.1 / \mathrm{sec}$ and $10^{-5} / \mathrm{sec}$ : (a) $15^{\circ}$, (b) $45^{\circ}$, (c) $60^{\circ}$, and $(\mathrm{d}) 75^{\circ}$.

seen that the composites response is hardly affected by the fiber cross-section shape; with the increasing of fiber volume fraction and fiber off-axis orientation, the effects of fiber cross-sectional shape become more obvious. Among the three kinds of fiber shapes, the stiffest response is obtained for the composites with the square fibers and the most compliant response for the composites with the circular fibers.

(3) The increasing of fiber volume fraction can improve the stiffness of AS4/PEEK composite. However, for the elliptical fiber, the maximum allowable fiber volume fraction is 0.59 in the case of fibers with an aspect ratio of $4 / 3$, so it should be noted that the elliptical fiber may not be chosen when the fiber volume fraction needed is big.

(4) The influence of fiber off-axis orientation on the stress-strain curves of AS4/PEEK composite is very large. The response of composites decreases obviously when the off-axis orientation changes from $15^{\circ}$ to $45^{\circ}$ and then increases from $60^{\circ}$ to $90^{\circ}$. So when the composites have been chosen to bear the load, the fiber off-axis orientation should be paid attention to.

\section{Conflict of Interests}

The authors declare that there is no conflict of interests regarding the publication of this paper. 

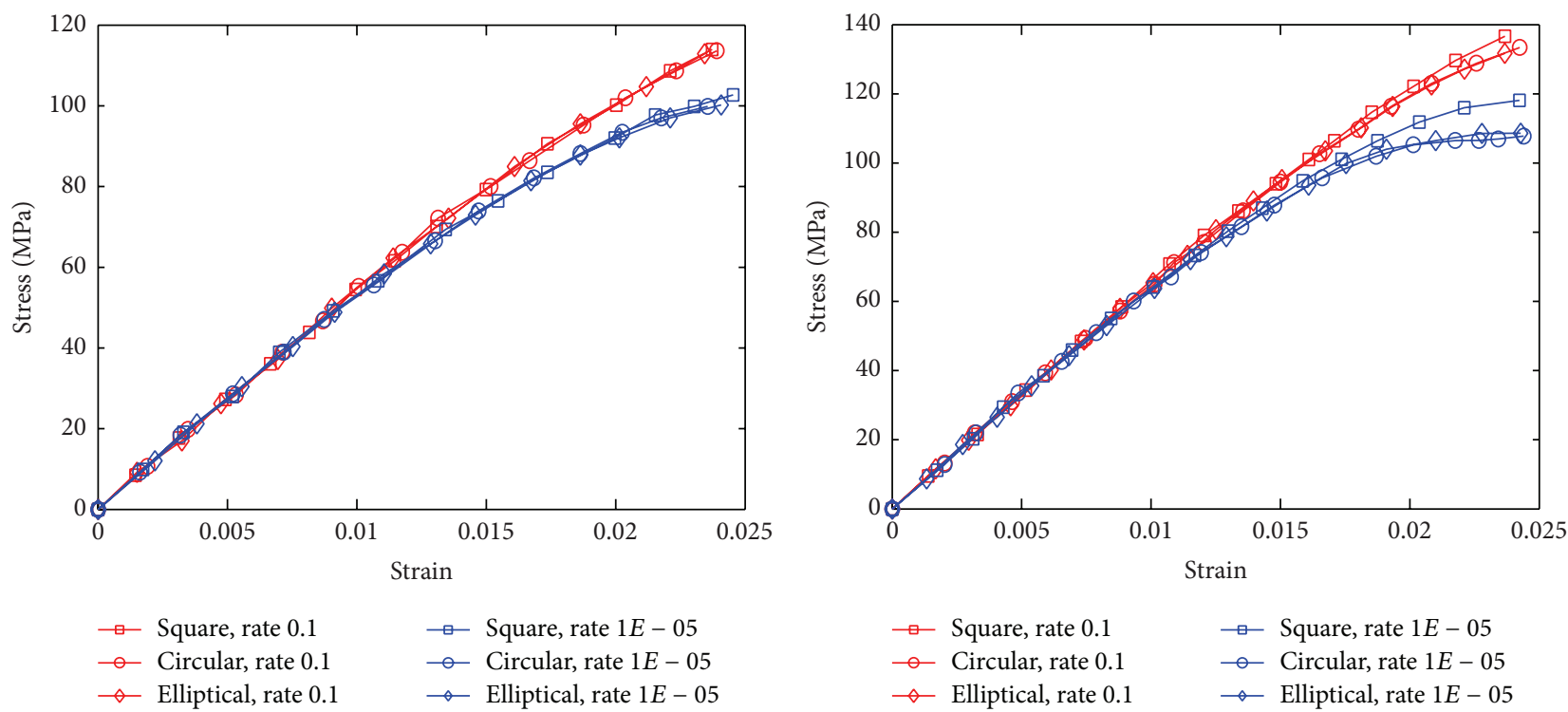

(a)

(b)

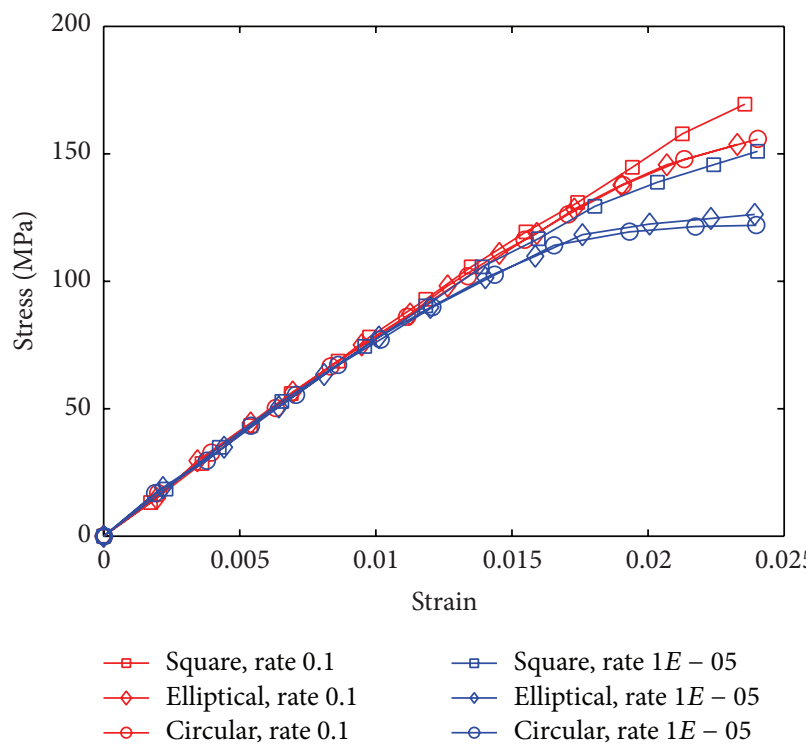

(c)

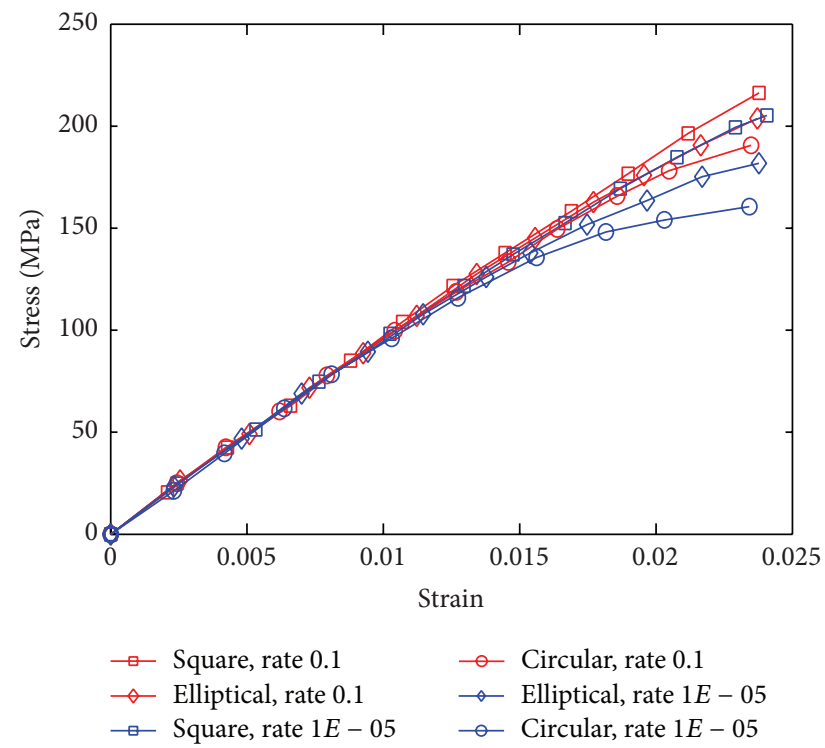

(d)

FIGURE 10: Stress-strain response of AS4/PEEK $\left[90^{\circ}\right]$ laminate at strain rate of $0.1 / \mathrm{sec}$ and $10^{-5} / \mathrm{sec}$ : (a) $v_{f}=0.15$, (b) $v_{f}=0.30$, (c) $v_{f}=0.45$, and (d) $v_{f}=0.55$.

\section{Acknowledgments}

This work was supported by the National Natural Science Foundation of China (nos. 51175401 and 51335006), the Research Fund for the Doctoral Program of Higher Education of China (no. 20120201110028), and the Program for Changjiang Scholars and Innovative Research Team in University.

\section{References}

[1] D. Motamedi, A. Milani, M. Komeili, M. Bureau, F. Thibault, and D. Trudel-Boucher, "A stochastic XFEM model to study delamination in PPS/glass UD composites: effect of uncertain fracture properties," Applied Composite Materials, vol. 21, no. 2, pp. 341-358, 2014.

[2] P. W. R. Beaumont, "Targeting problems of composite failure," Key Engineering Materials, vol. 417-418, pp. 37-40, 2010.

[3] Y. Zhou and Z. Huang, "A bridging model prediction of the ultimate strength of composite laminates subjected to triaxial loads," Journal of Composite Materials, vol. 46, no. 19-20, pp. 2343-2378, 2012.

[4] A. Riccio, A. Raimondo, and F. Scaramuzzino, "A study on skin delaminations growth in stiffened composite panels by a novel numerical approach," Applied Composite Materials, vol. 20, no. 4, pp. 465-488, 2013. 
[5] R. K. Goldberg, G. D. Roberts, and A. Gilat, "Incorporation of mean stress effects into the micromechanical analysis of the high strain rate response of polymer matrix composites," Composites B: Engineering, vol. 34, no. 2, pp. 151-165, 2003.

[6] G. M. Pearce, A. F. Johnson, R. S. Thomson, and D. W. Kelly, "Experimental investigation of dynamically loaded bolted joints in carbon fibre composite structures," Applied Composite Materials, vol. 17, no. 3, pp. 271-291, 2010.

[7] C. A. Weeks, Nonlinear rate dependent response of thick-section composite laminates [Ph.D. thesis], Purdue University, 1995.

[8] S. V. Thiruppukuzhi and C. T. Sun, "Models for the strainrate-dependent behavior of polymer composites," Composites Science and Technology, vol. 61, no. 1, pp. 1-12, 2001.

[9] A. Haque and M. Ali, "High strain rate responses and failure analysis in polymer matrix composites-an experimental and finite element study," Journal of Composite Materials, vol. 39, no. 5, pp. 423-450, 2005.

[10] M. M. Shokrieh and M. J. Omidi, "Tension behavior of unidirectional glass/epoxy composites under different strain rates," Composite Structures, vol. 88, no. 4, pp. 595-601, 2009.

[11] J. Ye, Y. Qiu, Z. Zhai, and X. Chen, "Strain rate influence on nonlinear response of polymer matrix composites," Polymer Composites, 2014.

[12] Z. Zhai, Z. He, X. Chen, J. Ye, and X. Zhu, "Fiber cross-section shape effect on rate-dependent behavior of polymer matrix composites with FBGs sensors," Sensors and Materials, vol. 25, no. 6, pp. 403-410, 2013.

[13] C. A. Weeks and C. T. Sun, "Modeling non-linear ratedependent behavior in fiber-reinforced composites," Composites Science and Technology, vol. 58, no. 3-4, pp. 603-611, 1998.

[14] S. V. Thiruppukuzhi and C. T. Sun, "Testing and modeling high strain rate behavior of polymeric composites," Composites B: Engineering, vol. 29, no. 5, pp. 535-546, 1998.

[15] H. D. Espinosa, H. Lu, P. D. Zavattieri, and S. Dwivedi, "A 3-D finite deformation anisotropic visco-plasticity model for fiber composites," Journal of Composite Materials, vol. 35, no. 5, pp. 369-410, 2001.

[16] E. Kontou and A. Kallimanis, "Thermo-visco-plastic behaviour of fibre-reinforced polymer composites," Composites Science and Technology, vol. 66, no. 11-12, pp. 1588-1596, 2006.

[17] W. Hufenbach, A. Hornig, B. Zhou, A. Langkamp, and M. Gude, "Determination of strain rate dependent through-thickness tensile properties of textile reinforced thermoplastic composites using L-shaped beam specimens," Composites Science and Technology, vol. 71, no. 8, pp. 1110-1116, 2011.

[18] L. Raimondo, L. Iannucci, P. Robinson, and P. T. Curtis, "Modelling of strain rate effects on matrix dominated elastic and failure properties of unidirectional fibre-reinforced polymermatrix composites," Composites Science and Technology, vol. 72, no. 7, pp. 819-827, 2012.

[19] L. Xing, K. L. Reifsnider, and X. Huang, "Progressive damage modeling for large deformation loading of composite structures," Composites Science and Technology, vol. 69, no. 6, pp. 780-784, 2009.

[20] J. Ye, X. Chen, Z. Zhai, B. Li, Y. Duan, and Z. He, "Predicting the elastoplastic response of fiber-reinforced metal matrix composites," Mechanics of Composite Materials, vol. 46, no. 4, pp. 405-416, 2010.

[21] D. D. Robertson and S. Mall, "Micromechanical relations for fiber-reinforced composites using the free transverse shear approach," Journal of Composites Technology and Research, vol. 15, no. 3, pp. 181-192, 1993.
[22] R. K. Goldberg and D. C. Stouffer, "Strain rate dependent analysis of a polymer matrix composite utilizing a micromechanics approach," Journal of Composite Materials, vol. 36, no. 7, pp. 773793, 2002.

[23] A. Tabiei and S. B. Aminjikarai, "A strain-rate dependent micro-mechanical model with progressive post-failure behavior for predicting impact response of unidirectional composite laminates," Composite Structures, vol. 88, no. 1, pp. 65-82, 2009.

[24] Z. Huang, "Simulation of the mechanical properties of fibrous composites by the bridging micromechanics model," Composites A: Applied Science and Manufacturing, vol. 32, no. 2, pp. 143172,2001

[25] Z.-M. Huang, "Inelastic and failure analysis of Laminate structures by ABAQUS incorporated with a general constitutive relationship," Journal of Reinforced Plastics and Composites, vol. 26, no. 11, pp. 1135-1181, 2007.

[26] M. Paley and J. Aboudi, "Micromechanical analysis of composites by the generalized cells model," Mechanics of Materials, vol. 14, no. 2, pp. 127-139, 1992.

[27] S. Ogihara, S. Kobayashi, and K. L. Reifsnider, "Characterization of nonlinear behavior of carbon/epoxy unidirectional and angle-ply laminates," Advanced Composite Materials, vol. 11, no. 3, pp. 239-254, 2003.

[28] J. Tsai and K. Chen, "Characterizing nonlinear rate-dependent behaviors of graphite/epoxy composites using a micromechanical approach," Journal of Composite Materials, vol. 41, no. 10, pp. 1253-1273, 2007.

[29] A. Gilat, R. K. Goldberg, and G. D. Roberts, "Strain rate sensitivity of epoxy resin in tensile and shear loading," Journal of Aerospace Engineering, vol. 20, no. 2, pp. 75-89, 2007.

[30] M.-J. Pindera and B. A. Bednarcyk, "An efficient implementation of the generalized method of cells for unidirectional, multiphased composites with complex microstructures," Composites B: Engineering, vol. 30, no. 1, pp. 87-105, 1999.

[31] D. C. Stouffer and L. T. Dame, Inelastic Deformation of Metals: Models, Mechanical Properties, and Metallurgy, John Wiley \& Sons, New York, NY, USA, 1996.

[32] R. K. Goldberg, G. D. Roberts, and A. Gilat, "Implementation of an associative flow rule including hydrostatic stress effects into the high strain rate deformation analysis of polymer matrix composites," Journal of Aerospace Engineering, vol. 18, no. 1, pp. 18-27, 2005. 


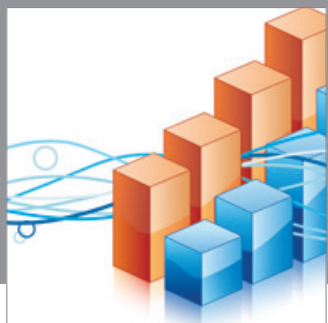

Advances in

Operations Research

mansans

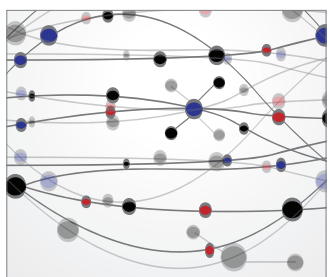

The Scientific World Journal
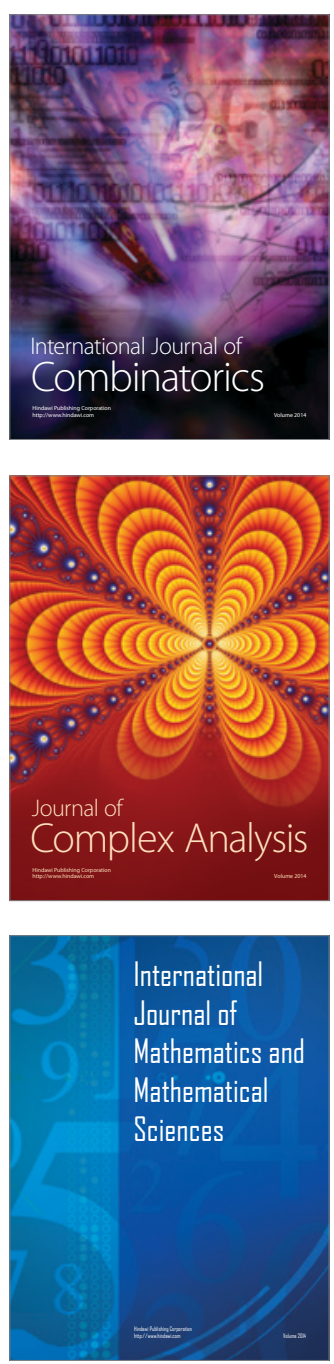
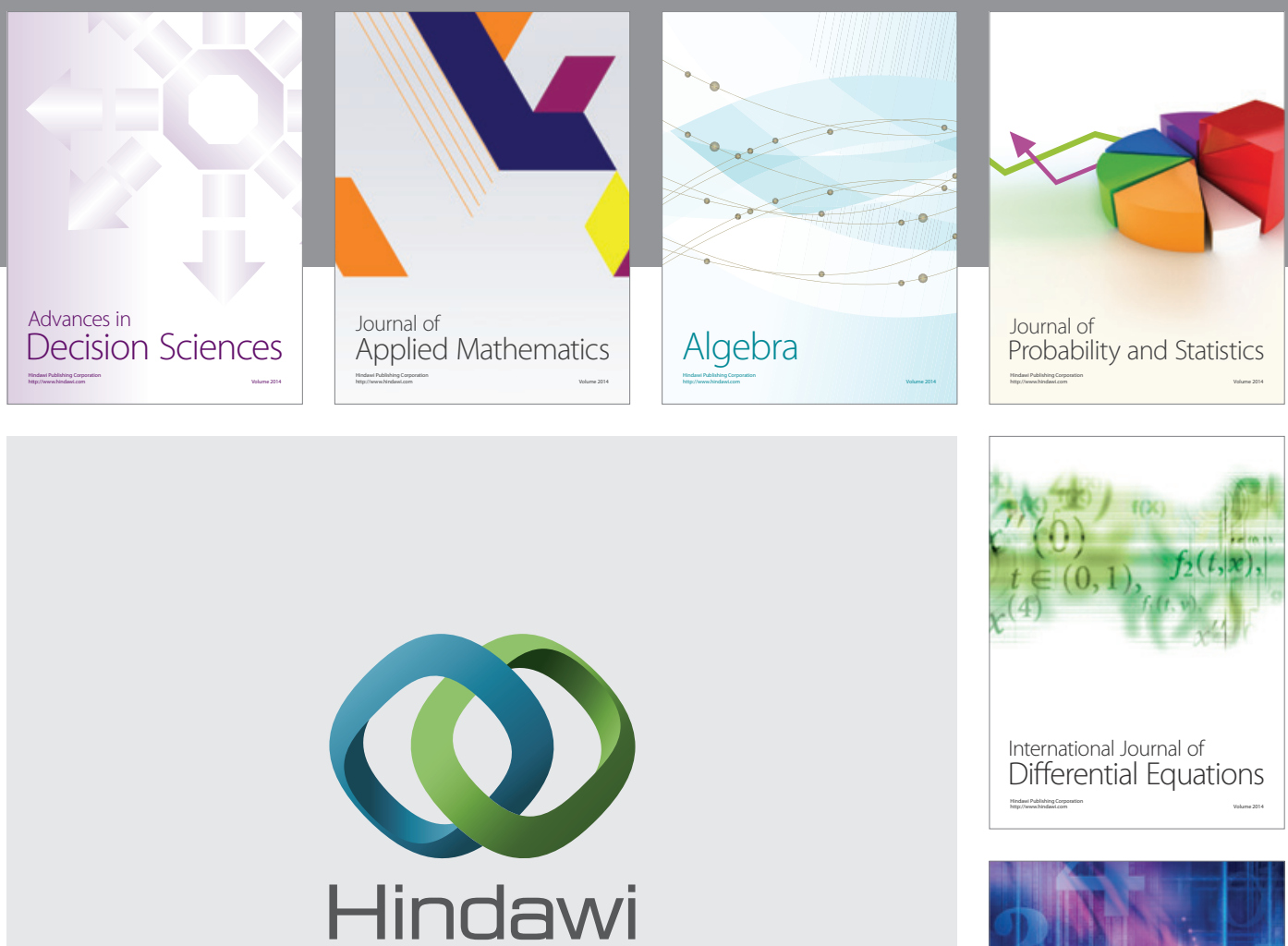

Submit your manuscripts at http://www.hindawi.com
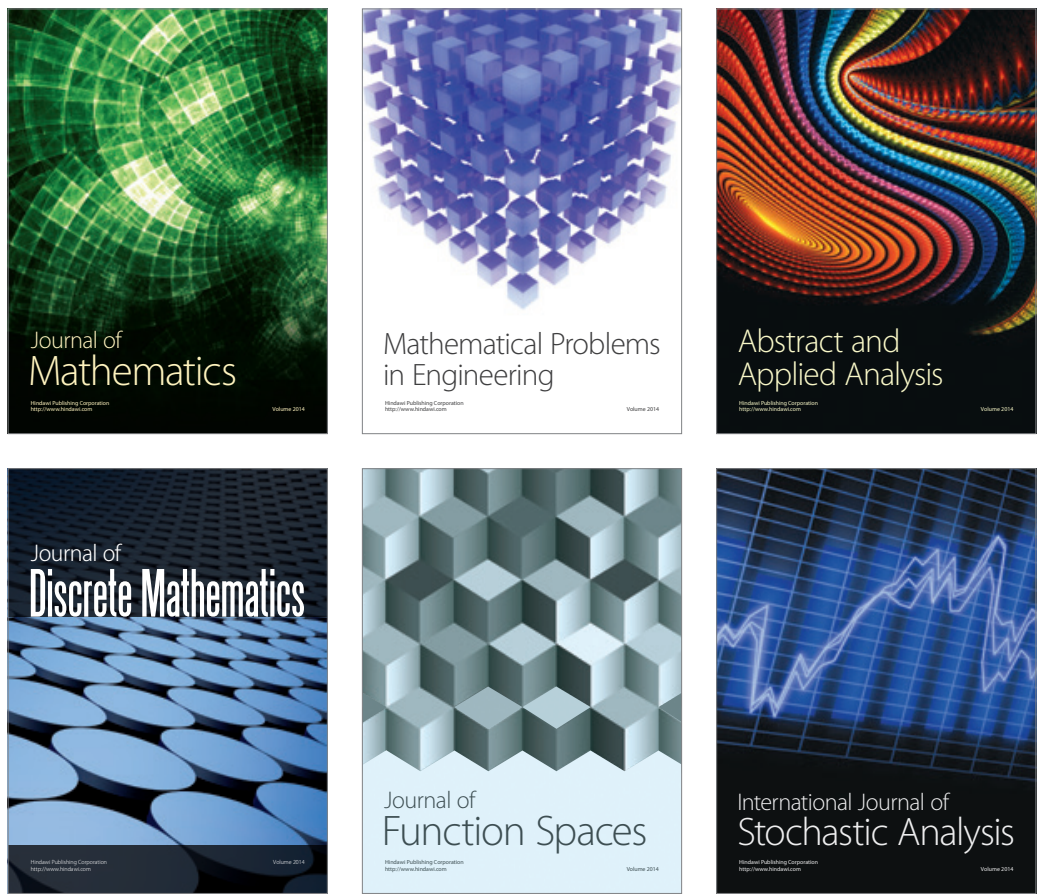

Journal of

Function Spaces

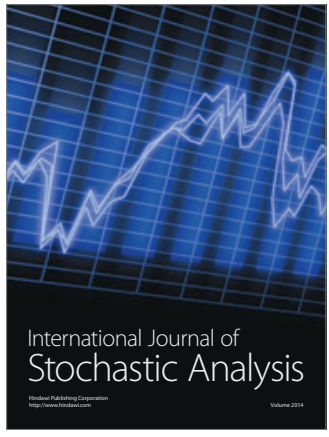

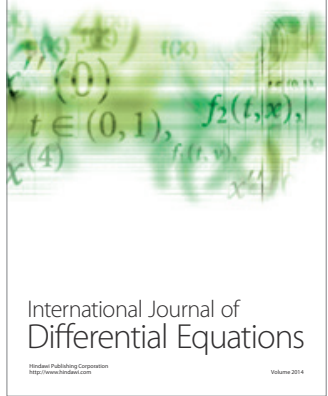
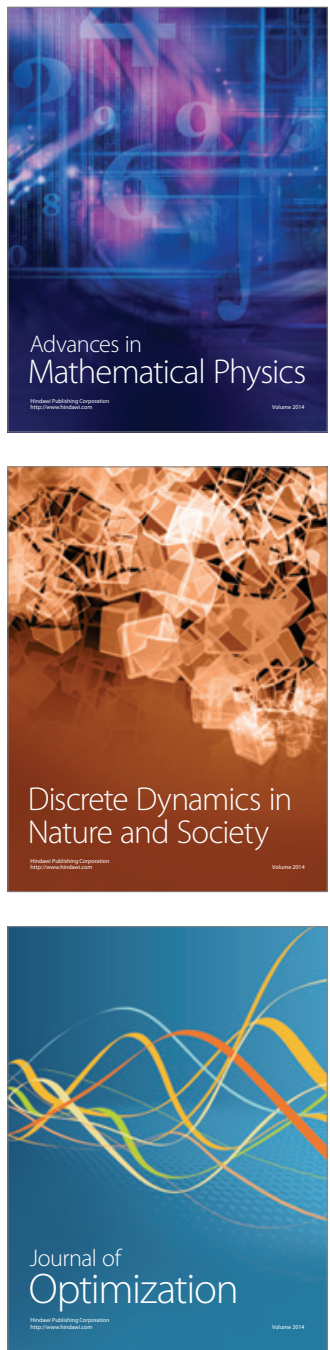